\title{
Vivências e Elaborações sobre a Tentativa de Suicídio na Adolescência: Estudo de Caso Fenomenológico
}

\author{
Life Experiences and Elaborations about the Suicide Attempt at the Adolescence: \\ Phenomenological Case Study
}

\section{Vivencias y Elaboraciones sobre el Intento de Suicidio en la Adolescencia: un Estudio de Caso Fenomenológico}

\author{
Andersson José Aparecido de Oliveira \\ Roberta Vasconcelos Leite \\ Yuri Elias Gaspar ${ }^{1}$ \\ Universidade Federal dos Vales do Jequitinhonha e Mucuri (UFVJM)
}

\begin{abstract}
Resumo
A tentativa de suicídio, fenômeno complexo, é problema de saúde pública: índices são alarmantes. Objetivamos apresentar estudo de caso fenomenológico sobre como adolescente que tentou suicídio elabora essa experiência. Realizamos entrevista semiestruturada com uma adolescente, analisada fenomenologicamente. Resultados exaltam situações de sofrimento existencial: tristeza, solidão, ressentimento por se perceber criticada e rejeitada em relações familiares e afetivas. Quando tentou suicídio, rejeições foram vividas de forma totalizante, obliterando outros sentidos da existência. Essa tentativa, elaborada como impulsiva, incide em como se percebe e relaciona com o outro: alguns a estigmatizam enquanto outros a acolhem e compreendem, mobilizando novas elaborações sobre si e seu mundo-da-vida. Discutimos como a experiência após tentativa não consumada pode ser mais dramática que a anterior ao ato. Concluímos ser urgente compreender consequências de como se lida com quem tentou se matar, destacando a importância do cuidado para que a pessoa elabore sua experiência com abertura e autenticidade.
\end{abstract}

Palavras-chave: tentativa de suicídio, adolescência, fenomenologia, pesquisa qualitativa

\section{Abstract}

Suicide attempt, a complex phenomenon, is a public health problem: rates are alarming. We aim to present a phenomenological case study on how a teenager who attempted suicide elaborates this experience. We conducted a semi-structured interview with a teenager, analyzed phenomenologically. Results highlight situations of existential suffering: sadness, loneliness, resentment for being criticized and rejected in family and affective relationships. When she attempted suicide, rejections were fully lived, obliterating other senses of existence. This attempt, elaborated as impulsive, focuses on how one perceives and relates to the other: some stigmatize her while others welcome and understand her, mobilizing new elaborations about herself and her life-world. We discussed how the experience after an unsuccessful attempt can be more dramatic than the pre-act experience. We conclude that it is urgent to understand the consequences of dealing with those who tried to kill themselves, highlighting the importance of care for the person to elaborate their experience with openness and authenticity.

Keywords: suicide attempt, adolescence, phenomenology, qualitative research

\section{Resumen}

El intento de suicidio, un fenómeno complejo, es un problema de salud pública: las tasas son alarmantes. Nuestro objetivo es presentar un estudio de caso fenomenológico sobre cómo una adolescente que intentó suicidarse elabora esta experiencia. Realizamos una entrevista semiestructurada con una adolescente, analizada fenomenológicamente. Los resultados destacan situaciones de sufrimiento existencial: tristeza, soledad, resentimiento por ser criticada y rechazada en las relaciones familiares y afectivas. Cuando intentó suicidarse, los rechazos fueron vividos en su totalidad, destruyendo otros sentidos de la existencia. Este intento, elaborado como impulsivo, se centra en cómo una percibe y se relaciona con el otro: algunos la estigmatizan mientras que otros la acogen y la entienden, movilizando nuevas elaboraciones sobre si misma y su mundo de la vida. Discutimos cómo la experiencia después de un intento fallido puede ser más dramática que la

\footnotetext{
${ }^{1}$ Endereço para contato: Universidade Federal dos Vales do Jequitinhonha e Mucuri, Faculdade Interdisciplinar em Humanidades, sala 80, Rodovia MGT 367, Km 583, n 5000, Alto da Jacuba, Diamantina, MG. E-mail: yuri.gaspar@ufvjm.edu.br
} 
experiencia previa al acto. Concluimos que es urgente comprender las consecuencias de cómo tratar aquellos que intentaron suicidarse, destacando la importancia de lo cuidado para que la persona elabore su experiencia con apertura y autenticidad.

Palabras clave: intento de suicidio, adolescencia, fenomenología, investigación cualitativa

\section{Introdução}

Atualmente, vivemos numa época caracterizada pelo individualismo (Lipovetsky, 2004), pela fluidez e fragilidade das relações (Bauman, 2007), pela disseminação do vazio existencial (Frankl, 1994) e pela carência de um eixo de valores supraordenados comum a todos, o que resulta numa sociedade que se define pelo pluralismo (Berger \& Luckmann, 2012). Tais características, ainda que não esgotem a realidade social contemporânea, delimitam certa estrutura de mundo que potencializa condições para a difusão de crises subjetivas e intersubjetivas de sentido (Berger \& Luckmann, 2012). Entre várias consequências pessoais e sociais ligadas a tais crises, vê-se o aumento dos índices de suicídios, sendo que, em alguns países, os índices são alarmantes.

Do ponto de vista epidemiológico, a questão já é considerada pela Organização Mundial da Saúde como problema de saúde pública: a cada ano, mais de 800.000 pessoas morrem por suicídio no mundo, sendo esta a segunda principal causa de morte entre 15 e 29 anos. Entre as mortes violentas de homens, 50\% são por suicídios e, entre mulheres, esse percentual sobe para 71\% (World Health Organization [WHO], 2014).

No Brasil, entre 2010 e 2014, foram registradas 50.664 mortes por suicídio, sendo a taxa média de mortalidade de 5,23 por 100.000 habitantes (Dantas et al., 2018). O coeficiente de mortalidade por suicídios é considerado relativamente baixo em comparação com a média mundial (o que pode ser decorrência de subnotificação), mas em números absolutos o país figura entre os dez países com mais ocorrências, índice preocupante que cresce consideravelmente ao longo das últimas décadas (Botega, 2014). Estima-se que, entre 1994 e 2004, houve um aumento de $35,1 \%$ nas taxas de suicídios - número superior às mortes por acidentes de trânsito no mesmo período (Aquino, 2009). Neste contexto, inúmeras pesquisas destacam a importância da formação dos profissionais de saúde para atuação na prevenção, pós-venção e atendimento nas unidades de urgência (Avanci, Pedrão, \& Costa Júnior, 2005; Chaves et al., 2015; Faro \& Santos, 2018).

Destaca-se que as taxas mencionadas não contemplam as tentativas de suicídio, que são exponencialmente maiores que as de suicídio letal, embora existam poucos mapeamentos sistemáticos a respeito (Faro \& Santos, 2018). Para cada suicídio consumado, estudos brasileiros estimam que dez tentativas de suicídio foram realizadas (Botega, 2014; Dutra, 2000), enquanto pesquisas internacionais chegam a mencionar 30 tentativas (United States Department of Health and Human Services [HHS], 2012). Para Botega (2014), tentativas de suicídio precisam ser levadas a sério, porque são sinais de alerta de que o contexto psicossocial não vai bem. Pesquisas apontam também aumento nas tentativas de suicídio e suicídio consumado na adolescência (Dutra, 2000; Freitas, 2005), bem como de condutas autolesivas (fortemente associadas às tentativas e ideações suicidas) que, nessa etapa da vida, podem se configurar como forma de sinalizar sofrimento ou tentar modificar comportamentos de outras pessoas (Faro \& Santos, 2018). 
É verdade que, enquanto fenômeno propriamente humano, o suicídio esteve presente ao longo da história, sendo vivido, compreendido e elaborado de formas diferentes, dependendo de cada contexto sócio-histórico-cultural (Corrêa \& Barrero, 2006). No entanto isso não diminui a gravidade do problema, despertando a atenção de diferentes perspectivas na busca por compreendê-lo na atualidade. Quais fatores podem estar desencadeando a decisão de interromper o próprio ciclo do desenvolvimento humano? A resposta não pode ser simplista, pois se trata de fenômeno multifatorial, implicando fatores biológicos, pessoais, sociais, culturais e históricos (Aquino, 2009; Cassorla, 2004; Dutra, 2000). Estudos como o de Dantas et al. (2018) explicitam como fatores isolados não dão conta da complexidade da questão: seus dados mostram que, no Brasil, a mortalidade por suicídio tem baixa ou nenhuma relação com fatores socioeconômicos e fraca correlação espacial.

Enquanto fenômeno humano, multifatorial, também não é correto enquadrá-lo exclusivamente no rol das patologias mentais, embora a literatura científica (Botega, 2014; Waiselfisz, 2014) aponte tais agravos como fatores de risco. Alguns autores defendem que suicídio "em última análise, constitui-se de uma decisão pessoal que não se pode esclarecer nem explicar" (Lukas, 1992 apud Aquino, 2009, p. 119). Reconhecemos que existem suicídios (no plural): trata-se de um ato complexo (Kovács, 1992) e é importante apreender um continuum que caracteriza esse fenômeno, que contempla desde a ideação, a tentativa e o suicídio consumado (Cassorla, 2004).

Acerca da ideação e da tentativa de suicídio, Frankl (2015) e Angerami-Camon (2017) identificam o vazio existencial como fator relevante para desencadeá-las, sobretudo na adolescência, fase de transição, de intensos questionamentos e de elaboração de identidade (Erikson, 1998; Duarte, 2015). O vazio existencial configura-se como ausência generalizada de sentido que incide na experiência das pessoas e traz consequências como: frustração, angústia, perda do gosto de viver, sensação de futilidade/tédio e isolamento social.

Como corolário, a dimensão do sentido apresenta-se como fundamental na prevenção do fenômeno do suicídio em nosso contexto social e histórico (Angerami-Camon, 2017). Isto é, quem tem um "para quê" viver tem mais condições de elaborar sua experiência com o sofrimento (Frankl, 2015). O sentido então é critério que influencia na pergunta "vale a pena continuar a viver?". E, quando a vida perde o sentido, deixar de viver pode surgir como possibilidade; no entanto a presença do outro pode ser companhia que ajude a pessoa que tentou se matar a elaborar sua experiência e ressignificar a sua vida (Frankl, 2005, 2015; Landsberg, 2009).

Portanto, diante da diversidade de fatores que perpassam o fenômeno em análise, reconhecemos a importância da questão existencial na vivência e elaboração da tentativa de suicídio. Objetivamos, neste trabalho, apresentar estudo de caso fenomenológico, em que investigamos de que modo uma adolescente que tentou se matar elabora essa experiên$\mathrm{cia}^{2}$. Esperamos que as compreensões daí advindas possam fornecer aportes àqueles que investigam o fenômeno e, particularmente, possam contribuir para a atuação daqueles que acompanham pessoas que atentaram contra a própria vida, seja em âmbito profissional, seja em âmbito pessoal.

\footnotetext{
${ }^{2}$ Agradecemos à Fundação de Amparo à Pesquisa do Estado de Minas Gerais (FAPEMIG) pelo apoio institucional e financeiro para a realização desta pesquisa.
} 


\section{Metodologia}

Adotamos a Fenomenologia Clássica proposta por Husserl (2006, 2012) e Stein (2003, 2005) como perspectiva teórico-metodológica. Esta abordagem, que busca apreender a mútua constituição sujeito-mundo por meio da análise da estrutura da vivência em sua unidade e complexidade, revela-se propícia para nossa investigação, que toma a experiência como centro para compreensão do fenômeno do suicídio.

Interessados em analisar a experiência do suicídio a partir da elaboração da pessoa, realizamos pesquisa qualitativa de tipo estudo de caso, seguindo as diretrizes fenomenológicas (Gaspar, 2014). ${ }^{3}$ Como participante, selecionamos uma jovem de 19 anos, moradora de uma cidade de pequeno porte do interior de São Paulo, que tentou se matar quando tinha 14 anos. Os critérios para essa amostragem intencional foram: ter realizado uma tentativa de suicídio e ter interesse e disponibilidade para compartilhar suas elaborações sobre o acontecimento.

Realizamos coleta de dados, em momento propício à elaboração, por meio de entrevista fenomenológica semiestruturada, cuidando para facilitar que a participante descrevesse sua experiência (e não opiniões sobre o assunto) (Amatuzzi, 2008). Adotamos a seguinte pergunta disparadora, intencionalmente mais ampla para dar espaço para a pessoa adentrar no tema do suicídio se e quando quisesse e se sentisse confortável: "Gostaria que você me contasse a sua experiência de vida, descrevendo os momentos significativos bons e/ou difíceis que você viveu ao longo de seu percurso". Ao longo da entrevista, buscamos romper com os tradicionais tabus e preconceitos em torno do tema, respeitando sua dinâmica de elaboração ao mesmo tempo em que cuidávamos em auxiliá-la a retomar o foco na experiência sempre que necessário e a esclarecer pontos de especial interesse para os objetivos de nossa pesquisa (Barreira \& Ranieri, 2013).

Gravada em registro sonoro, a entrevista foi integralmente transcrita observando-se os estilos de linguagem da participante e incluindo dados não verbais reveladores de suas vivências no momento, como expressões faciais e corporais, olhares e gestos expressivos. Posteriormente, realizamos a textualização da transcrição, de modo a facilitar a leitura e compreensão da experiência comunicada, buscando preservar sua vitalidade e complexidade original (Leite \& Mahfoud, 2010). No tópico "Resultados", grafamos em itálico os termos retirados da transcrição da entrevista e destacamos também entre aspas trechos longos da fala da participante que não estão recuados em relação ao texto.

A análise dos dados guiou-se pelo método fenomenológico (Van der Leeuw, 1964), que toma os relatos como expressões das vivências e escava a subjetividade e o mundo-da-vida. Reconhecendo que não há possibilidade de apreensão direta das vivências do outro, esse procedimento volta-se à delimitação de sua estrutura: totalidade orgânica compreendida que emerge como "desenho" traçado no caótico emaranhado da realidade. Trata-se de uma reconstrução operada pelo investigador com vistas a descrever o fenômeno compreendido a partir dos diversos sentidos que se abrem ao sujeito.

Para tanto, Van der Leeuw (1964) propõe como diretrizes metodológicas: (1) nomeação de conjuntos de vivências para organizá-las e torná-las inteligíveis; (2) inserção metódica na própria vida, buscando colher conscientemente como as vivências do outro ressonam,

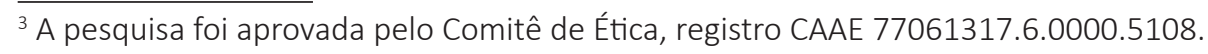


indicando sentidos a serem compreendidos; (3) inserção entre parênteses (epochè), de modo a suspender a facticidade e as convicções pessoais prévias para captar o sentido do fenômeno; (4) elucidação das vivências por meio de categorias que ressaltam as conexões de sentido entre elas; (5) compreensão das conexões de sentido e, quando possível, elaboração da conexão típica ideal; (6) Retificação contínua das compreensões alcançadas, que realizamos voltando aos dados colhidos, ao próprio sujeito de pesquisa e/ou recorrendo a fontes como referencial teórico e espaços coletivos de discussão acadêmica; (7) Reconstrução da experiência vivida para sua apresentação, cuidando de favorecer o acesso à vitalidade das vivências analisadas.

\section{Resultados}

Luna ${ }^{4}$ conta-nos que esta entrevista foi a primeira vez que conseguiu falar abertamente sobre sua experiência de tentar se matar. Seu relato foi sintético, marcado por longos silêncios, fortes emoções e elaborações solicitadoras sobre o processo vivido.

O sentimento de tristeza pela percepção da falta de apoio dos familiares marca o modo como Luna elabora sua relação com seu círculo mais íntimo. Mesmo dizendo que ela e seus irmãos sejam amados da mesma forma pela mãe, a experiência de rejeição norteia sua percepção de si. E, em sua elaboração, essa rejeição faz com que viva uma experiência constante de carência e, por consequência, de solidão:

"A verdade é que tenho um problema muito sério comigo mesma que se chama solidão, carência, e aquela sensação de não ter ninguém comigo (emocionada), mesmo sabendo que tem pessoas que me amam, que sei que posso contar". Para Luna, trata-se de "problema muito sério", algo que lhe emociona. Em sua experiência, solidão não é estar sozinha, pois ela sabe que tem pessoas que lhe amam, com quem pode contar. Solidão é, mesmo sabendo do amor do outro, perceber-se sozinha. Solidão é carência, é não ter ninguém comigo.

A partir do modo como Luna elabora sua relação com seus familiares, podemos perceber como a relação com quem lhe é próximo do ponto de vista consanguíneo não necessariamente se traduz em termos de intimidade e acolhimento. Pelo contrário, o que Luna percebe é rejeição - o que Ihe deixa triste - e ausência, que é vivida como solidão. Luna, mesmo quando cercada por familiares, sente não ter ninguém com quem compartilhar a vida.

E o que significa para ela definir a solidão como problema "muito sério"? Acompanhemos:

Eu percebo que isso é um problema mais que sério porque. . . Já comecei a passar na psicóloga e ... eu não consigo. Eu ... Eu não tenho paciência, eu sou uma pessoa antissocial, gosto de ficar reservada, trancada no meu quarto, sozinha. As pessoas às vezes me chamam pra conversar no Facebook, eu não consigo ... Interagir é muito difícil, porque às vezes eu acho que ficar calada é melhor . . . (Após longo silêncio, lágrimas vertem de seus olhos).

Em sua elaboração, trata-se de problema mais que sério por impossibilitar uma abertura para se relacionar com o outro. "Eu não consigo ..." Luna repete, mais de uma vez, sobre sua dificuldade de interagir, seja presencialmente, com a psicóloga, seja virtualmente, por meio do Facebook. Por vezes, essa dificuldade é "explicada" por sua falta de paciência ou por

\footnotetext{
${ }^{4}$ Luna é o nome fictício escolhido pela própria entrevistada. Preservamos sua identidade, deixando-a livre para escolher um codinome para nomeá-la na investigação.
} 
característica pessoal ("sou uma pessoa antissocial"), ou ainda, simplesmente, por preferência: "gosto de ficar reservada, trancada no meu quarto, sozinha". Mas, mesmo diante das tentativas de explicação, fica evidente que o fato mesmo é vivido com dor, como experiência que the emociona profundamente e que dificulta o relacionamento com o outro e consigo mesma. Tanto é que Luna, diante dessas explicações, por fim, afirma com lágrimas nos olhos: "Interagir é muito difícil, porque às vezes eu acho que ficar calada é melhor . . .".

Quanto mais Luna adentra sua experiência de solidão, mais se evidencia para nós que não se trata pura e simplesmente de um traço de personalidade inato. Luna se isola por se perceber rejeitada, ela se tranca por não encontrar ressonância. Há uma carência que, de certo modo, se estrutura também como ressentimento e que a silencia, pois Ihe dói: “. . . ficar calada é melhor. . ."? Continuemos a acompanhá-la:

Porque sempre que às vezes eu conto pra alguém, sempre estou errada, sou criticada; então, às vezes, prefiro guardar pra mim certas coisas do que contar e acabar piorando a situação ... (Novamente se emociona e permanece um longo tempo em silêncio).

Na sua elaboração, em todas as vezes que se abriu, foi julgada e criticada, culminando com o agravamento da situação. Em resposta a tudo isso: ". . . prefiro guardar pra mim e às vezes eu acho que assim eu vou vivendo".

Aqui se torna mais claro porque Luna afirma que não tem ". . ninguém comigo, mesmo sabendo que tem pessoas que me amam, que sei que posso contar". Em sua experiência, isso significa não ter ninguém com quem possa se abrir, compartilhar suas questões, seus problemas, suas dores. E, depois de tentar e não conseguir, preferiu se fechar, guardar para si. É assim que ela vai vivendo, embora perceba que esse jeito de viver é um problema, algo que novamente the emociona, que Ihe faz ficar em silêncio repleto de dor.

A partir de sua elaboração, podemos compreender a situação de sofrimento existencial na qual Luna se vê imersa. Ao retomar suas relações familiares, expõe continuamente sua tristeza, solidão, carência, dificuldade de se abrir e de se relacionar, ressentimento por se perceber rejeitada, julgada e criticada. $\mathrm{O}$ isolamento se estrutura e passa a ser visto como modo de vida possível, mas extremamente dolorido. E o silêncio, ausência de palavras, revelador de vivências profundamente dolorosas, algumas das quais não temos acesso, enquanto outras são rápida e parcialmente reveladas:

Um dos momentos mais ruins [sic] da minha vida foi quando tentaram abusar de mim, uma mágoa que eu carrego. Mesmo que eu não queira, carrego pra minha vida, dentro comigo, aqui. Perdas que eu já tive, de pessoas especiais... (Longo silêncio e olhos lacrimejados). Ah, pode pular essa parte, né?

O abuso, as perdas de pessoas especiais, são algumas experiências (des)veladas, mágoas que Luna carrega consigo, dentro de si. Para ela, estes são alguns dos piores momentos de sua vida, momentos que ela optou - ou não conseguiu - nos contar com maior detalhamento, mas que podemos perceber como foram e permanecem sendo provocadores de grande sofrimento.

No entanto, durante a entrevista, Luna se dispôs a compartilhar conosco outra experiência dolorosa para ela: a tentativa de suicídio: "Você quer que eu comente da minha experiência de quando eu tentei me matar?". 
Naquela noite eu tinha acabado de chegar [em casa] . . Eu estava com meu ex-namorado. Nós discutimos e ele começou a me xingar de biscate, de vadia, começou a me ofender: falou que pra ele eu não era nada, que tudo não passou de fingimento. E eu estava lavando louça, e eu...

Meu pai e eu também tínhamos acabado de discutir e ele me disse umas coisas que não gostei. No meio de tudo isso eu comecei a chorar . . . só chorava, só chorava . . . aí fui lavar a louça e passou pela minha cabeça que a única forma de acabar com tudo e não sofrer mais era .. ."Vou tomar aquilo [produto para limpeza de alumínio] que assim eu morro e tanto faz, acaba de uma vez com tudo".

A partir do modo como Luna revisita essa experiência, percebemos como ela elabora a tentativa de se matar estabelecendo uma ligação entre discussões em que se viu violentada, o sofrimento daí advindo e os pensamentos (e posterior "decisão") de findar com a própria vida. Se, "de fato", houve esta relação "direta", ou se esta foi a "razão" da tentativa, não nos cabe aqui conjecturar. É evidente que o suicídio é mais complexo e não se reduz a um único fator, não sendo este o ponto sobre o qual nos debruçaremos agora. O que podemos compreender é que, em sua elaboração, relações circunscritas despertaram sofrimentos existenciais que, num determinado momento, passaram a ocupar a totalidade da vida. Aquela dor tornou-se tudo. E, para não sofrer mais, Luna "decide" acabar com tudo, isto é, acabar com a própria vida.

Naquele momento já me desceu queimando tudo, e gritei a minha mãe. Falei "tá queimando, tá queimando". Nisso eu já não conseguia mais conversar, ela gritou, meu irmão correu, me colocou dentro do carro e fomos para o hospital. Lá fizeram a lavagem, colocaram a sonda...

Depois disso meu estômago nunca mais foi o mesmo, não é tudo que eu posso comer. Estou sentindo dores. Já estou indo atrás de fazer exames e sinto que não está normal e até hoje eu me arrependo. Foi um momento de besteira, de bobeira, não valeu a pena (entre lágrimas).

No momento em que tenta se matar, Luna sente a dor física decorrente e, num ato que indica arrependimento, grita por sua mãe em busca de ajuda. Ela relembra o drama de não mais conseguir falar, o afã de seus familiares e as consequências imediatas e duradouras de seu gesto: seu "estômago nunca mais foi o mesmo".

Em sua elaboração, a tentativa de ceifar a própria vida foi um ato impulsivo, um "momento de besteira". E as dores físicas permanecem, bem como o arrependimento: não valeu a pena. No entanto não foram somente as consequências físicas que Ihe machucaram e ainda permanecem. Há também outras consequências:

"Fora de risco", Luna se abre, explicando os motivos que a levaram a tentar se matar, e passa então a enfrentar o julgamento condenatório do outro. Em sua elaboração, enquanto sua mãe, "chateada", queria Ihe bater por considerar aquele ato não razoável, "por causa de homem!", seu pai a deixaria morrer, por ter se considerado desrespeitado em sua autoridade paterna, "eu estava respondendo ele".

No modo como Luna elabora sua tentativa de suicídio, podemos compreender como o olhar do outro significativo pode condenar e "aumentar" ainda mais a dor vivida. Luna sofria 
quando tentou se matar e, mesmo arrependida, passa a ser julgada negativamente pelo ato no qual não se reconhece mais. E, para ela, tão grave quanto as consequências físicas enfrentadas são também a não compreensão e a condenação outro:

É difícil porque a todo momento parece que eles estão zombando, "tirando onda" com minha cara. Mas às vezes têm uns que entendem, né. Os que entendem que foi apenas um momento de besteira e que ficaram pelo menos felizes pelo fato de saberem que eu me arrependi. Me arrependi de tudo o que fiz. Muitos me julgaram. Muitos até hoje me julgam, mas isso não me abala não. Não me abala mais ...

Na experiência de Luna, há aqueles que zombam, que "tiram onda", isto é, que julgam negativamente e reforçam o olhar condenatório. No entanto há também aqueles que entendem, que reconhecem se tratar de um ato impulsivo, que ficam felizes por saber que ela se arrependeu, isto é, que acolhem, compreendem e oferecem uma forma diferente de se relacionar sem reduzi-la à tentativa de suicídio.

A partir dessas elaborações, fica evidente a complexidade da questão e delicadeza que ela requer. Muitas vezes, olhamos somente para os motivos que levam alguém a se matar, enquanto o relato de Luna exacerba também a importância de compreendermos as consequências e os diferentes modos de como se pode lidar com alguém que tentou se matar e sobreviveu.

Por um lado, mesmo arrependida, Luna muitas vezes é julgada e reduzida ao comportamento suicida. Vai se constituindo um estigma que pode marcar a pessoa por toda a vida. E o sofrimento anterior, que já era vivido e elaborado como profundamente doloroso, é potencializado (o que, segundo as pesquisas indicam, pode contribuir para que a pessoa pense e tente novamente se matar). ${ }^{5}$ Por outro lado, Luna é acolhida e compreendida por alguns em sua experiência e arrependimento, o que pode abrir caminho para novas formas de elaborar o próprio sofrimento. Hoje, ela afirma conseguir se posicionar sem se definir pelo julgamento do outro: mesmo expressando a dor ao ser reduzida ao seu ato, chega a dizer que isso não the abala mais.

Quais fatores ajudam Luna a elaborar essa questão?

Depois disso me fez enxergar que: quem sou eu para tentar tirar a minha vida? A única Pessoa que pode tirar minha vida é Deus. Assim como Ele me deu só Ele tem o direito de tirar, não eu. Às vezes hoje estou pagando o preço pelo que fiz. (Silêncio).

A tentativa de suicídio e as experiências daí advindas foram tomadas como ocasião para que Luna reelaborasse o modo como lida com a própria vida a partir de uma experiência religiosa: Deus é apresentado como "única Pessoa que pode tirar minha vida". Podemos compreender que, a partir dessa experiência religiosa, Luna encontra um sentido para o sofrimento vivido. "Pagando o preço" pelo que fez, sofrendo e suportando as consequências dos seus atos, Luna agora afirma: "Eu não tinha esse direito", pois, para ela, foi Deus quem Ihe deu a vida. Nesse ponto do relato, seu silêncio manifesta-se de forma diversa, indicando outros significados: seu silêncio sugere reflexão.

Além desse fator que hoje orienta sua elaboração, Luna retoma também "bons momentos" vividos em sua trajetória de vida:

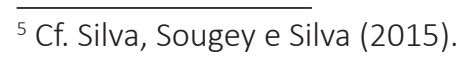


São amizades que tenho que me influenciam muito. Mesmo distante sei que se preocupam comigo ... Às vezes, algumas festas entre amigos que sei que são verdadeiros, que não é nada de bagunça. . . Está todo mundo ali da minha família reunida. Aí se traz aquela sensação de paz, de harmonia. . . Ah, deixa eu ver: o aprendizado que estou vivendo...

Luna evidencia a complexidade de suas relações e juízos, tematizando as pessoas significativas que lhe fazem bem, que provocam sensação de paz, de harmonia: aquelas relações verdadeiras, amigos que se preocupam com ela, familia reunida, aprendizado. A partir de suas elaborações, podemos compreender como o outro é radical em sua elaboração, e o modo como ele se relaciona com ela abre caminho para experiências de solidão, violência, sofrimento ou para experiências de acolhimento, compreensão, autenticidade. É na relação que Luna pode se ferir, bem como pode se abrir - para si e para o outro. E, quando a relação se estrutura como abertura, pode emergir gratidão:

Eu te agradeço, porque, de qualquer forma, me sinto como se eu tivesse tirado um peso, uma coisa aqui dentro, uma coisa que eu não tenho o costume de contar para ninguém como estou me sentindo, como eu estou. Isso me fez bem!

Gratidão também compartilhada por nós. Retomar a própria trajetória é ocasião preciosa para encontrar e se encontrar. Luna, refletindo sobre suas experiências, por mais dolorosas que sejam, vive o gosto de ter "tirado um peso". Falar a partir de si, a partir de dentro, mesmo não tendo o costume, faz bem! Percebemos assim o caráter terapêutico dessa entrevista. Compreendemos que, sendo empáticos, ouvindo o outro com atenção e compreensão, facilitamos que a pessoa elabore sua experiência com o sofrimento, tirando daí um aprendizado.

\section{Discussão}

A partir da análise e reconstrução da experiência vivida por Luna, destacaremos algumas questões buscando contribuir para a compreensão da tentativa do suicídio em sua complexidade.

Ao adentrar a estrutura da vivência descrita, compreendemos como a relação se revela fundamental para a constituição da subjetividade. Seja nos momentos de maior sofrimento, seja nas experiências de correspondência e realização, a relação com o outro emerge como ponto significativo a partir do qual a pessoa toma a si mesma e o mundo a sua volta. Vários são os pensadores que se debruçam sobre a radicalidade do outro para a constituição de si mesmo, como Buber (2004) e Stein (2003), por exemplo.

Em consonância com nossas compreensões, Freitas (2005), em estudo qualitativo etnográfico com doze adolescentes, observa que o suicídio nessa faixa etária se mostrou ligado à não aceitação do término de um relacionamento amoroso, agressões verbais dentro do ambiente familiar somadas à falta de carinho e atenção, em suas palavras, ao "amor não correspondido". Essa autora ainda constatou a incidência de um situação-limite: nas suas pesquisas, apreende que a frustração com o outro marcado pela traição num relacionamento amoroso foi evento decisivo para a tentativa de suicídio. Contudo ressalta que suicídio "não acontece fora de um sistema social, ainda que os indivíduos pareçam estar isolados da sociedade" (Freitas, 2005, p. 76). 
E, a partir da experiência de Luna, pudemos acompanhar como as relações intersubjetivas podem ser disruptivas, gerando violência, sofrimento, solidão. Como apontado por Mahfoud (2018), trata-se de solidão como incomunicabilidade, "impossibilidade de que a pessoa apresente-se por completo nos relacionamentos e nas ações no mundo" (p. 424), culminando em isolamento e sofrimento psíquico. Para Angerami-Camon (2017), a experiência da solidão, compreendida como "configuração extremada da ausência do outro" (p. 27), pode associar-se diretamente ao desespero e, por fim, ao suicídio. Como vimos, a solidão e os sofrimentos vividos se estruturam na experiência de Luna, abrindo caminho para que determinadas situações violentas sejam vividas, como frustração e desespero existencial último, sendo elaboradas por ela como "estopim" para sua tentativa de se matar.

Luna vivia vazio existencial descrito por Frankl (2015) e Angerami-Camon (2017)? A análise empreendida não permite afirmar que sim ou não, mas suas elaborações indicam como a rejeição é tomada de forma totalizante, obliterando no momento da tentativa de autoextermínio quaisquer outros sentidos que pudessem sustentar a continuidade da existência. A seguir, relações de cuidado e sua experiência religiosa são elaboradas como sentidos que sustentam seu arrependimento e empenho em continuar vivendo. A partir de sua experiência, a discussão sobre a constituição do sentido da vida não pode ser desvinculada da centralidade das relações, suscitando reflexões sobre como a abertura estrutural ao outro pode ser vivida - e frequentemente o é, em nossa sociedade - tanto como fator de risco quanto fator de proteção às tentativas de suicídio.

No entanto, como pontuado na análise, muitas investigações debruçam-se sobre fatores de risco ou proteção, ocupando-se das razões pelas quais a pessoa tentou se matar. Acompanhando Luna, inquietamo-nos com o que acontece após a tentativa do suicídio. Vimos como ela elabora as consequências físicas do ato, mas, sobretudo, destaca como o olhar condenatório do outro marca o modo como vive e elabora a própria experiência. 0 estigma do "suicida" se estrutura e, muitas vezes, a pessoa que tentou se matar passa a ser reduzida àquele ato.

A partir de revisão de literatura sobre o tema, Silva, Sougey e Silva (2015) destacam como os rótulos pejorativos associados ao suicídio, como fraqueza, falta de fé, loucura, má índole familiar, entre outros, pouco contribuem para a compreensão, detecção, prevenção ou acompanhamento das pessoas que tentaram se matar. Além disso, segundo os autores, sem o apoio da sociedade e das esferas governamentais, o estigma tende a se intensificar, dificultando ainda mais o enfrentamento do tema, bem como pode contribuir para o ". . . desencadeamento de novos motivos para a tentativa, por parte do indivíduo, bem como novas fases de desestruturação e conflito, para a família" (Silva et al, 2015, p. 424).

Particularmente preocupantes são os achados de Freitas (2005) e Avanci et al. (2005), que evidenciam como é comum que profissionais da saúde, nas unidades de emergência, reproduzam preconceitos e estigmatização, amplificando o sofrimento da pessoa que tentou se matar, por meio de falas agressivas ou condutas que, deliberadamente, buscam infligir dor a esses pacientes, como forma de "castigo".

Luna não relata agressões desse tipo específico, mas vive relações em que é estigmatizada. Ao mesmo tempo, ela encontra pessoas que a acolhem e compreendem, abrindo caminho para novas elaborações sobre si e sobre seu mundo-da-vida. Nesse sentido, o cuidado emerge como um fator crucial que pode contribuir para que a pessoa consiga 
elaborar a própria experiência numa posição de abertura e autenticidade. Como esta compreensão pode iluminar a atuação de profissionais de saúde, familiares ou amigos que acompanham pessoas que sobreviveram à tentativa de suicídio?

Faro e Santos (2018) alertam que não há soluções simples, convocando os profissionais ao aprimoramento contínuo de suas práticas. Já Fukumitsu e Sousa (2015), ao discutirem possibilidades de cuidado na psicoterapia com pessoas que tentaram suicídio, diferenciam o "cuidar de" do "cuidar com". O "cuidar de" evidencia uma hierarquia de poder entre alguém que sabe algo sobre a psique e o outro que sofre psicologicamente e, portanto, necessita de cuidado. O "cuidar com" significa elaborar com o sujeito uma experiência significativa, ouvi-lo atentamente, acolher a sua experiência, a sua pessoa e, assim, ajudá-lo a "assumir o seu próprio fazer" (Fukumitsu \& Sousa, 2015, p. 30).

Avançando nessa direção do "cuidar com", acreditamos que a possibilidade do encontro genuíno e a vivência do cuidado (cuidar-e-ser-cuidado) podem também ser vividas em outros espaços. As clínicas (médica, psicológica etc.) são locais substanciais de cuidado; no entanto podemos extrapolar a experiência de cuidado para todas as relações. O encontro com Luna nos testemunhou como, até mesmo no papel de pesquisadores, à medida que cuidamos da experiência do outro, compartilhamos com ele a nossa presença. Ficamos disponíveis a ele e tornamo-nos depositários de experiências singulares e, antes mesmo de nos darmos conta, passamos a fazer parte da sua biografia existencial.

\section{Considerações Finais}

A tentativa de suicídio é um fenômeno complexo que carece de mapeamentos sistemáticos (Faro \& Santos, 2018), bem como de mais estudos qualitativos. A investigação sobre este tema, a partir da experiência de uma adolescente que tentou se matar, permitiu-nos compreender diversos fatores que o constituem, além trazer provocações significativas.

Partindo de reflexões sobre nosso contexto histórico e cultural, apresentamos dados sobre a amplificação dos casos de suicídio em nossa sociedade, particularmente entre adolescentes. Instigados pelas contribuições de Frankl (1994, 2005, 2015), perguntamo-nos sobre a incidência do vazio existencial nesse fenômeno e nos debruçamos sobre as elaborações de Luna sobre a tentativa de se matar. Suas vivências chamaram nossa atenção para processos que, a princípio, não havíamos previsto e que outras pesquisas tantas vezes negligenciam: as elaborações e os sofrimentos que ocorrem após a tentativa não consumada, que podem ser ainda mais dilacerantes que os fatores desencadeantes do ato. Discutindo esses achados com a literatura da área, enfatizamos a importância da disponibilidade de ouvir e "cuidar com".

Reconhecendo que este estudo de caso não pode ser generalizado para a compreensão de quaisquer modalidades de tentativa de suicídio, entendemos que suas contribuições se situam particularmente nas perguntas que podem ser articuladas a partir da experiência de Luna. O que a decisão de morrer do outro nos comunica enquanto sociedade? Como sobreviver perante frustrações existenciais depois de uma atitude de autoextermínio não consumado e encontrar resiliência para permanecer vivo no mundo? Como reencontrar uma razão para viver em um contexto ainda mais limitante que aquele que levou uma vez a desistir da vida? Como romper com os estigmas sociais que giram em torno da pessoa que tentou 
se matar? Como ajudar a pessoa a não se tomar somente por aquele ato? Como ajudar o outro a olhar para a experiência de quem tentou se matar, numa posição compreensiva de abertura e de não julgamento? Como fomentar relações de cuidado no mundo contemporâneo marcado, muitas vezes, pelo individualismo? De que modos experiências significativas de sentido poderiam contribuir para a prevenção e o acompanhamento de pessoas que tentaram suicídio?

São provocações que não se esgotam e que convocam posicionamento. Com elas, reafirmamos a importância de acolher a experiência da pessoa que buscou extinguir a própria existência como passo importante para a compreensão do suicídio e caminho para formular possíveis intervenções. Àqueles que são convocados a lidar com situações desse tipo - seja por dever profissional, seja por proximidade no círculo de relações pessoais -, fica o apelo de que tantas "Lunas" invisibilizadas em nossa sociedade cotidianamente nos fazem em seus silêncios e dores: ser empático e estar atento à pessoa que sofre diante desse desejo angustiante de querer morrer, acolhendo-a na sua singularidade e ajudando-a a elaborar o sentido ontológico, é fundamental para lidar com a situação de forma verdadeiramente humana.

\section{Referências}

Amatuzzi, M. M. (2008). Por uma psicologia humana (2a ed.). Campinas: Alínea.

Angerami-Camon, V. A. (2017). Solidão a ausência do outro (5a ed.). Belo Horizonte: Artesã. Aquino, T. A. A. (2009). Atitudes e intenções de cometer o suicídio: seus correlatos existenciais e normativos. (Tese de Doutorado, Centro de Ciências Humanas, Letras e Artes, Universidade Federal da Paraíba, João Pessoa, PB).

Avanci, R. C., Pedrão, L. J., \& Costa Júnior, M. L. (2005). Tentativa de suicídio na adolescência: considerações sobre a dificuldade de realização diagnóstica e a abordagem do profissional de enfermagem. SMAD - Revista eletrônica saúde mental álcool e drogas, 1(1), 1-8. Recuperado de http://pepsic.bvsalud.org/scielo. php?script=sci_arttext\&pid=S1806-69762005000100007\&lng=pt\&tIng=pt

Barreira, C. R. A., \& Ranieri, L. P. (2013). Aplicação das contribuições de Edith Stein à sistematização de pesquisa fenomenológica em psicologia: a entrevista como fonte de acesso às vivências. In M. Mahfoud, \& M. Massimi (Orgs.), Edith Stein e a psicologia: teoria e pesquisa (pp. 449-466). Belo Horizonte: Artesã.

Bauman, Z. (2007). Tempos Líquidos. Rio de Janeiro: Zahar.

Berger, P. \& Luckmann, T. (2012). Modernidade, pluralismo e crise de sentido: a orientação do homem no mundo moderno (3a ed.). (E. Orth, Trad.). Petrópolis, RJ: Vozes.

Botega, N. J. (2014). Comportamento suicida: epidemiologia. Psicologia USP, 25(3), 231-236. Buber, M. (2004). Eu e Tu. (N. A. von Zuben, Trad.). São Paulo: Centauro. (Original publicado em 1923).

Cassorla, R. M. S. (2004). Suicídio e autodestruição humana. In B. G. Werlang \& N. J. Botega (Orgs.), Comportamento suicida (pp. 21-33). Porto Alegre: Artmed.

Chaves, A. A., Macedo, M. R. C., Cordeiro, C. A. F., Leite, E. O., Mendes, L. P., Almeida, S. J. M., Halboth, N. V. (2015). Prevenção de suicídios: é importante que todos estejam preparados? Capacitação 2014. In Anais da IV Semana integração do ensino, pesquisa e extensão da UFVJM. (p. 247). Diamantina: UFVJM. 
Corrêa, H., \& Barrero, S. P. (Orgs.). (2006). Suicídio: Uma morte evitável. São Paulo: Atheneu. Dantas, A. P., Azevedo, U. N., Nunes, A. D., Amador, A. E., Marques, M. V., \& Barbosa, I. R. (2018). Analysis of suicide mortality in Brazil: spatial distribution and socioeconomic context. Brazilian Journal of Psychiatry, 40(1), 12-18. doi:https://doi. org/10.1590/1516-4446-2017-2241

Duarte, C. Z. C. G. (2015). Adolescência e sentido de vida. Curitiba: CRV.

Dutra, E. M. S. (2000). Compreensão de tentativas de suicídio de jovens sob o enfoque da abordagem centrada na pessoa. (Tese de Doutorado em Psicologia, Instituto de Psicologia, Universidade de São Paulo, São Paulo, SP).

Erikson, E. (1998). O ciclo de vida completo. São Paulo: Artmed.

Faro, A., \& Santos, L. C. S. (2018). Suicídio na adolescência: Panorama, cuidados e escuta. In V. A. Angerami (Org.), Sobre o suicídio: A psicoterapia diante da autodestruição (pp. 169189). Belo Horizonte: Artesã.

Frankl, V. E. (1994). Em busca de sentido: Um psicólogo no campo de concentração. Petrópolis, RJ: Vozes.

Frankl, V. E. (2005). Um sentido para a vida: Psicoterapia e humanismo (19a ed.). Aparecida, SP: Ideias e Letras.

Frankl, V. E. (2015). O sofrimento de uma vida sem sentido: Caminhos para encontrar a razão de viver. São Paulo: É Realizações.

Freitas, M. L. V. (2005). Razões para tentativas suicidas em adolescentes: Desafio para a educação em saúde. (Dissertação de Mestrado, Programa de Pós-Graduação em Saúde Coletiva, Universidade de Fortaleza, Fortaleza, CE).

Fukumitsu, K. O., \& Sousa, F. B. (2015). O cuidado como fator de proteção do suicídio. Revista Brasileira de Psicologia, 2(2), 28-32.

Gaspar, Y. E. (2014). Unidade na diversidade: Investigação fenomenológica de experiências de encontro inter-religioso. (Tese de Doutorado, Programa de Pós-Graduação em Psicologia, Universidade Federal de Minas Gerais, Belo Horizonte, MG).

Husserl, E. (2006). Idéias para uma fenomenologia pura e para uma filosofia fenomenológica. (M. Suzuki, Trad.). Aparecida, SP: Idéias e Letras. (Publicação original póstuma de 1952).

Husserl, E. (2012). A crise das ciências européias e a fenomenologia transcendental: Uma introdução à filosofia fenomenológica. (D. F. Ferrer, Trad.). São Paulo: Forense Universitária. (Publicação original póstuma de 1954).

Kovács, M. J. (Org.). (1992). Morte e desenvolvimento humano. São Paulo: Casa do Psicólogo. Landsberg, P. L. (2009). Ensaio sobre a experiência da morte e outros ensaios. Rio de Janeiro: Contraponto.

Leite, R. V., \& Mahfoud, M. (2010). Rigor e generalização em pesquisas sobre fenômenos culturais: contribuições de um percurso de pesquisas fenomenológicas. In Anais do IV Seminário Internacional de Pesquisa e Estudos. (pp. 1-9). São Paulo: SE\&PQ.

Mahfoud, M. (2018). Vale a pena viver? A pergunta radical requer resposta pessoal. In V. A. Angerami (Org.), Sobre o suicídio: A psicoterapia diante da autodestruição (pp. 423-433). Belo Horizonte: Artesã.

Lipovetsky, G. (2004). Os tempos hipermodernos. São Paulo: Barcarolla.

Silva, T. P. S, Sougey, E. B., \& Silva, J. (2015). Estigma social no comportamento suicida: reflexões bioéticas. Revista Bioética, 23(2), 419-426. 
Stein, E. (2003). Estructura de la persona humana. In E. Stein, Escritos antropológicos y pedagógicos (Obras Completas, Vol. 4, pp. 555-749). (F. J. Sancho et al., Trads.). Vitoria, Espanha: El Carmen. (Publicação original de 1932-1933).

Stein, E. (2005). Contribuciones a la fundamentación filosófica de la psicología y de las ciencias del espíritu. In E. Stein, Escritos filosóficos: Etapa fenomenológica (Obras Completas, Vol. 2, pp. 207-520). (F. J. Sancho et al., Trads.). Burgos, Espanha: Monte Carmelo. (Publicação original de 1922).

United States Department of Health and Human Services. (2012). 2012 National strategy for suicide prevention: Goals and objectives for action. Washington: HHS.

Van der Leeuw, G. (1964). Fenomenología de la religión. (E. de la Peña, Trad.). México: Fondo de Cultura Económica.

Waiselfisz, J. J. (2014). Mapa da violência: Os jovens do Brasil. Recuperado de http://www. mapadaviolencia.org.br/pdf2014/Mapa2014_JovensBrasil.pdf

World Health Organization. (2014). Preventing suicide: A global imperative. Geneva: World Health Organization. Recuperado de http://apps.who.int/iris/ bitstream/10665/131056/1/9789241564779_eng.pdf?ua=1

Recebido em: 23/09/2019

Última revisão: 14/10/2019

Aceite final: 23/11/2019

\section{Sobre os autores:}

Andersson José Aparecido de Oliveira: Bacharel em Humanidades pela Universidade Federal dos Vales do Jequitinhonha e Mucuri (UFVJM). Discente do curso de Fisioterapia na Universidade Federal dos Vales do Jequitinhonha e Mucuri (UFVJM). Bolsista de Iniciação Científica pela Fundação de Amparo à Pesquisa do Estado de Minas Gerais (FAPEMIG). E-mail: anderssoncristo@gmail.com, Orcid: http://orcid.org/0000-0001-7036-0309

Roberta Vasconcelos Leite: Doutorado em Psicologia pela Universidade Federal de Minas Gerais (UFMG). Mestrado e graduação em Psicologia pela UFMG. Professora da graduação do curso de Medicina e da pós-graduação do programa de pós-graduação em Ciências Humanas na Universidade Federal dos Vales do Jequitinhonha e Mucuri (UFVJM). E-mail: roberta.leite@ufvjm.edu.br, Orcid: http://orcid.org/0000-0003-3110-0509

Yuri Elias Gaspar: Doutorado, mestrado e graduação em Psicologia pela Universidade Federal de Minas Gerais (UFMG). Professor do bacharelado interdisciplinar em Ciências Humanas e da pós-graduação em Ciências Humanas na Universidade Federal dos Vales do Jequitinhonha e Mucuri (UFVJM).

E-mail: yuri.gaspar@ufvjm.edu.br, Orcid: http://orcid.org/0000-0002-4217-4848 